\title{
Sampling strategy and measurement device affect vaginal temperature outcomes in lactating dairy cattle
}

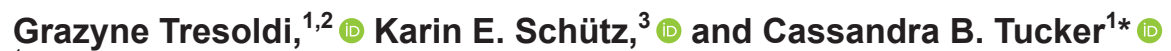 \\ ${ }^{1}$ Center for Animal Welfare, Department of Animal Science, University of California, Davis 95616 \\ ${ }^{2}$ College of Agriculture, California State University, Chico 95929 \\ ${ }^{3}$ AgResearch Ltd., Hamilton 3240, New Zealand
}

\section{ABSTRACT}

Body temperature (BT) is widely used to evaluate health and heat load status in cattle. Despite its importance, studies vary in how BT is measured and in the biological interpretation of the results. Costs, practicality, labor, and welfare concerns can affect how BT is measured, including frequency of measurement and the type of device used. Inaccurate BT outcomes may have implications for cattle welfare; for example, animals may only receive treatment when fever is identified. Our objectives were (1) to compare measurement of vaginal temperature (VT) using relatively small, inexpensive, and low-accuracy loggers $\left( \pm 0.5\right.$ to $\pm 1^{\circ} \mathrm{C}$, iButton range; Embedded Data Systems, Lawrenceburg, $\mathrm{KY})$ to a high-accuracy logger $\left( \pm 0.1^{\circ} \mathrm{C}\right.$; StarOddi, Gardabaer, Iceland), and (2) to evaluate how different BT sampling strategies correspond to 24-h VT in lactating dairy cows. To address the first objective, VT data from 54 cows were recorded every 45 min for $12 \mathrm{~d} /$ cow, on average, using 2 different types of temperature loggers (StarOddi DST centi-T and iButton DS1921H or DS1922L) attached to a shortened, hormone-free controlled internal drug release insert. Average VT obtained from both loggers were compared using mixed models and regression analyses. In addition, we tested the consistency of the low-accuracy loggers in detecting cows with elevated BT using the kappa coefficient of concordance. To address the second objective, VT data from 20 cows were recorded every min for 9 to $11 \mathrm{~d} /$ cow using StarOddi loggers. Using these data, we estimated average VT using 11 sampling strategies (every $5,10,15,30,45,60$, and $120 \mathrm{~min}, 1 \times / \mathrm{d}$ recorded in the morning or afternoon, $2 \times / \mathrm{d}$, or $3 \times / \mathrm{d}$ ). Estimates and observed means were compared using linear regression. Compared with StarOddi loggers, the iButtons either underestimated ( $\mathrm{H}$ model: 38.7 vs. $38.0 \pm 0.06^{\circ} \mathrm{C}$ ) or

Received March 21, 2019.

Accepted February 10, 2020.

*Corresponding author: cbtucker@ucdavis.edu overestimated VT (L model: 38.7 vs. $39.2 \pm 0.04^{\circ} \mathrm{C}$ ). When considering elevated or fever VT thresholds, iButtons did not correctly classify animals; kappa coefficients of concordance were $\leq 0.35$. Measuring VT as often as every $120 \mathrm{~min}$ resulted in more accurate estimates compared with strategies that recorded it once to thrice per day. These results indicate that the type of device (i.e., data logger) and sampling strategies affect BT outcomes and that these decisions affect the interpretation of BT data.

Key words: fever, hyperthermia, sampling interval, daily rhythm

\section{INTRODUCTION}

Body temperature (BT) has been widely used to detect disease (e.g., metritis, mastitis and pneumonia; Benzaquen et al., 2007; Adams et al., 2013) and how cattle respond to heat load (West et al., 2003; Kendall et al., 2007; Chen et al., 2013). Some have used it to aid estrus (Suthar et al., 2011; Polsky et al., 2017) and calving detection (Burfeind et al., 2011). Despite its importance, studies vary in how BT is measured and interpreted. The implications of interpretation are important for animal welfare; in some studies, BT was used to determine whether animals were eligible for treatment or not (Wenz et al., 2011; Pohl et al., 2016).

Body temperature can be recorded in different locations, with measurement devices that range in size and accuracy. Measurement of BT also varies by time of day and frequency over a 24-h period. Across studies, BT has been measured in the rectum (RT; Igono et al., 1985), vagina (VT; Kendall et al., 2006), reticulorumen (Adams et al., 2013), ear canal (Howard et al., 2013), eye (Hoffmann et al., 2013), milk (Pohl et al., 2014), and on both skin surface (Kaufman et al., 2018) and underneath the skin (Lee et al., 2016). In terms of devices, BT has been recorded using thermometer (RT) or infrared technology (skin), data loggers (RT, VT, ear, skin), and thermal imaging cameras (eye, skin). Device accuracy ranges from 1 to $0.1^{\circ} \mathrm{C}$ (Zimbelman 
et al., 2010; Burfeind et al., 2012), which is similar to treatment differences reported in the literature. Relatively low-accuracy devices may lead to more frequent type I and II errors, leading to unjustified drug use (e.g., false positive for fever) and animal welfare issues (e.g., false negative for fever), respectively. Thus, using high-accuracy loggers (i.e., $0.1^{\circ} \mathrm{C}$ ) may provide more reliable results and be considered the gold standard compared with those of lower accuracy.

Sampling frequency of BT is often associated with the device used to measure it. When using data loggers, it can be as often as every minute (Burfeind et al., 2011; Burdick et al., 2012; Suthar et al., 2013), whereas when using thermometers, BT is often measured once or twice a day (Benzaquen et al., 2007; Burfeind et al., 2011; Wenz et al., 2011). Although the latter is common, it is unclear whether infrequent measures are representative of the 24-h average or BT pattern throughout the day. Indeed, many studies have demonstrated that BT has a circadian pattern in cattle (Bitman et al., 1984; Araki et al., 1987; Liang et al., 2013) and that time of day can affect when $\mathrm{BT}$ reaches its minimum and maximum values. For example, VT amplitude (i.e., maximum minimum difference) of lactating cow VT ranged from 0.5 to $3.2^{\circ} \mathrm{C}$ across studies and cooling treatments in summer (Kendall et al., 2007; Chen et al., 2013, 2016a).

Differences in BT and its interpretation also vary across studies. When evaluating cooling strategies, for example, daily BT treatment differences ranges from 0.1 to $0.3^{\circ} \mathrm{C}$ (Means et al., 1992; Perano et al., 2015; Chen et al., 2016a). A similar range $\left(0.1\right.$ to $\left.0.2^{\circ} \mathrm{C}\right)$ was found when comparing the effects of cow characteristics (e.g., primiparous vs. multiparous cows; Wenz et al., 2011; Suthar et al., 2012) or health (e.g., cows with retained placenta vs. healthy counterparts; Vickers et al., 2010). Differences in $\mathrm{BT} \leq 1^{\circ} \mathrm{C}$ were also recorded in cows clinically diagnosed with mastitis or metritis compared with healthy controls (healthy vs. sick: 38.7 vs $39.6^{\circ} \mathrm{C}$ and 38.6 vs. $39.3^{\circ} \mathrm{C}$ for, respectively, metritis and mastitis; Benzaquen et al., 2007; Wenz et al., 2011). There is also considerable variation in the interpretation of absolute values. Temperature thresholds that define fever or hyperthermia range from as low as $38.9^{\circ} \mathrm{C}$ (Hillman et al., 2005) to as high as $40^{\circ} \mathrm{C}$ (Burfeind et al., 2012; Pohl et al., 2014), encompassing other values within this range: $39.2^{\circ} \mathrm{C}$ (Smith et al., 1998; Suthar et al., 2012; Polsky et al., 2017), $39.4^{\circ} \mathrm{C}$ (Benzaquen et al., 2007; Wenz et al., 2011), 39.5 $\mathrm{C}$ (Drillich et al., 2001; Burfeind et al., 2012; Pohl et al., 2014), and $39.7^{\circ} \mathrm{C}$ (Overton et al., 2003; Burfeind et al., 2012; Suthar et al., 2012).

Cost, practicality, labor, and welfare concerns affect how BT is measured, including frequency, the device used, and the location within the body (Lea et al., 2008; Burdick et al., 2012; Lee et al., 2016). For example, data loggers cost between $\$ 18$ (e.g., iButton DS1921H; Embedded Data Systems, Lawrenceburg, KY) and $\$ 280$ (DST centi-T logger; StarOddi, Gardabaer, Iceland) per device. Some data loggers require surgical procedures to insert them into the abdominal cavity or under the skin, whereas others may require braces or other attachments to hold them in place (Lea et al., 2008; Lee et al., 2016; Miura et al., 2017). To measure VT in dairy cows, smaller loggers can be inserted without any modifications to a hormone-free controlled internal drug release insert (CIDR; Burdick et al., 2012; Polsky et al., 2017).

The objectives of this study were (1) to compare BT outcomes when using a relatively small, inexpensive, and low-accuracy data logger (iButton, accuracy range: \pm 0.5 to $\pm 1^{\circ} \mathrm{C}$ ) to those of a high-accuracy logger (StarOddi, accuracy: $\pm 0.1^{\circ} \mathrm{C}$ ), and (2) to evaluate how sampling strategies correspond to 24-h BT in lactating dairy cows. To address these questions, we used VT, because we have been using this approach for several years. We predicted that an inexpensive, low-accuracy data logger and infrequent sampling would not match VT outcomes collected with a more expensive, highaccuracy logger and more frequent measurements. However, we predicted that the inexpensive, low-accuracy logger would still be useful to identify cows with elevated VT using different temperature thresholds (e.g., fever).

\section{MATERIALS AND METHODS}

Data for this study were collected during summer in 2015, 2016, and 2017 at the University of California, Davis Dairy Teaching and Research Facility. All procedures were approved by the UC Davis Institutional Animal Care and Use Committee (IACUC).

To address objective 1 (logger comparison), we conducted a prospective study using VT data from 54 cows enrolled in cooling trials to minimize animal use (Tresoldi et al., 2019; Drwencke et al., 2020). In 2016, we sampled 23 Holstein cows, averaging $36.7 \pm 3.8 \mathrm{~kg}$ of milk/d, $223 \pm 56$ DIM, $2 \pm 1$ lactations, and $95 \pm$ 52 d pregnant. In 2017, 22 Holstein and 9 Jersey cows were used. They averaged $34.0 \pm 5.0 \mathrm{~kg}$ of milk/d, 195 \pm 60 DIM, $2 \pm 1$ lactations, and $100 \pm 41 \mathrm{~d}$ pregnant. In both years, cows were housed in a freestall barn, being milked twice a day and fed a TMR 4 times a day.

Vaginal temperature was recorded simultaneously using 2 temperature loggers, one with high accuracy and one with low accuracy, for at least $6 \mathrm{~d}$ (average and maximum: 12 and $24 \mathrm{~d}$, respectively), in each cow. In 
both years, we recorded VT every 45 min using a DST centi-T logger (accuracy: $\pm 0.1^{\circ} \mathrm{C}$, resolution: $\pm 0.032^{\circ} \mathrm{C}$; StarOddi), and an iButton logger (Embedded Data Systems). In 2016, we used the DS1921H model (H model; accuracy: $\pm 1^{\circ} \mathrm{C}$, resolution: $\pm 0.125^{\circ} \mathrm{C}$ ) and, in 2017, the DS1922L model was used (L model; accuracy: $\pm 0.5^{\circ} \mathrm{C}$, resolution: $\pm 0.062^{\circ} \mathrm{C}$ ). The 2 data loggers were attached to a single shortened, hormone-free CIDR (DEC International NZ Ltd., Hamilton, New Zealand; Figure 1) using heat-shrink tubing (3M, St. Paul, MN). To ensure that both temperature sensors were measuring VT within the same location, they were adjacent in the "body" part of a single Y-shaped CIDR. Within a given year, all data loggers were launched and synchronized by the same computer, and thus measured temperature at the same time points throughout the day.

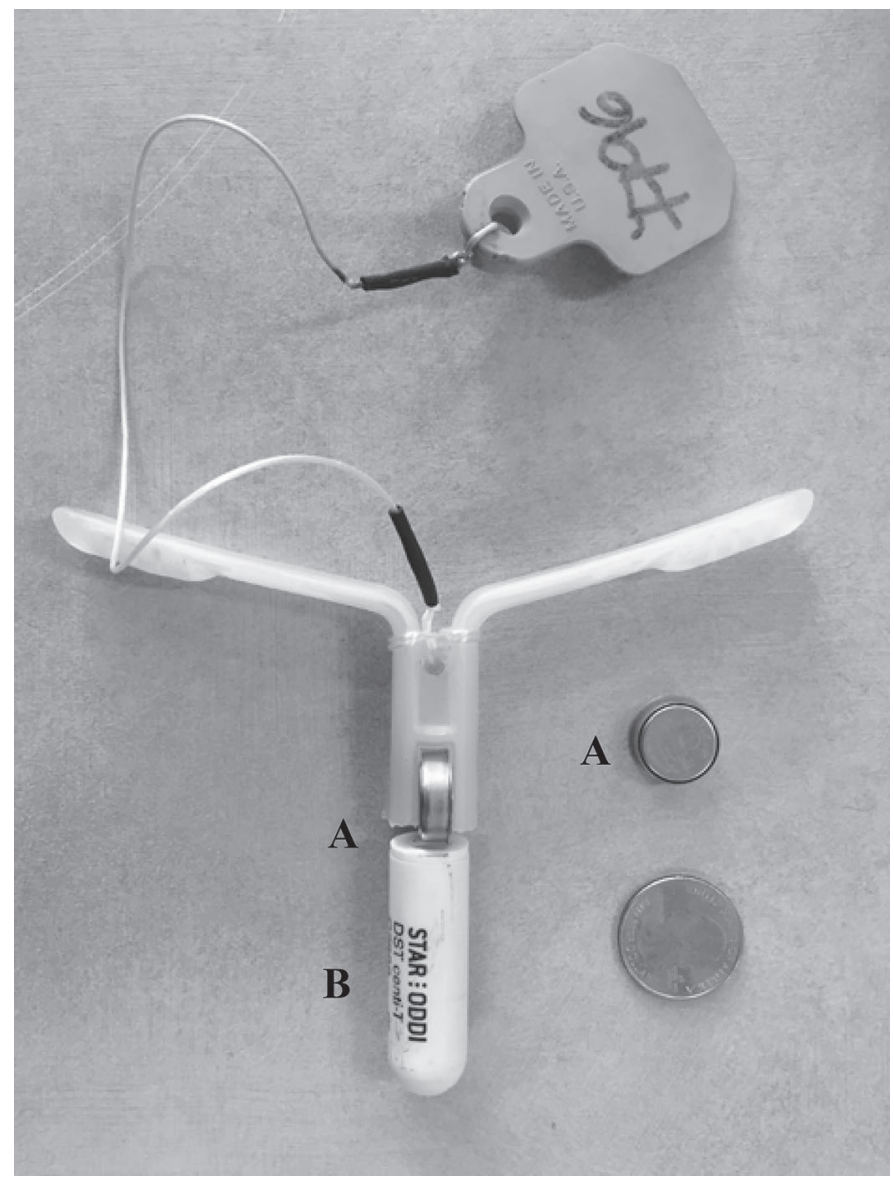

Figure 1. Vaginal temperature was recorded using 2 types of temperature data loggers: (A) iButton DS1921H or DS1922L models (Embedded Data Systems, Lawrenceburg, KY), and (B) StarOddi DST centi-T (StarOddi, Gardabaer, Iceland), which were attached to a shortened, hormone-free controlled internal drug release insert using heat shrink tubing (not shown in this picture).
To address objective 2 (sampling strategy), we conducted a retrospective study using VT data from 20 Holstein cows sampled in 2015 (Tresoldi et al., 2018). They averaged $38.9 \pm 4.2 \mathrm{~kg}$ of milk/d, $211 \pm 86$ DIM, $2 \pm 1$ lactations, and $119 \pm 52 \mathrm{~d}$ pregnant. Cows were kept in a freestall barn. They were milked and fed twice a day. Vaginal temperature was recorded every min for 9 to $11 \mathrm{~d}$ using DST centi-T loggers as described above.

A portable weather station (WS-16; Novalynx Corp., Auburn, CA) was placed in an open area, outside the barn and no more than $50 \mathrm{~m}$ away. Air and black globe temperatures (AT and $\mathrm{BGT},{ }^{\circ} \mathrm{C}$ ), wind speed (WS, $\mathrm{m} / \mathrm{s})$, relative humidity $(\mathrm{RH}, \%)$, solar radiation $(\mathrm{W} /$ $\left.\mathrm{m}^{2}\right)$, and precipitation $(\mathrm{mm})$ were recorded every 5 min. Additional measures of heat load were calculated including temperature-humidity index (THI) and heat load index (HLI), using the following equations from Kelly and Bond (1971) and Gaughan et al. (2008), respectively:

$$
\begin{gathered}
\mathrm{THI}=(1.8 \times \mathrm{AT}+32)-[(0.55-0.0055 \times \mathrm{RH}) \\
\times(1.8 \times \mathrm{AT}-26)] \\
\mathrm{HLI}=\text { if }[\mathrm{BGT}>25,8.62+(0.38 \times \mathrm{RH}) \\
+(1.55 \times \mathrm{BGT})+\exp (-\mathrm{WS}+2.4)-0.5 \times \mathrm{WS}], \\
\text { else }[10.66+(0.28 \times \mathrm{RH})+(1.3 \times \mathrm{BGT})-\mathrm{WS}] .
\end{gathered}
$$

\section{Data Management and Statistical Analysis}

Logger Comparison. All statistical analyses were carried out using SAS software (SAS Institute, 2014). Two approaches were used to compare the data loggers: one where we compared their overall performance to determine VT, and another where we compared their ability to identify cattle with elevated BT.

For the first approach, we compared individual VT overall averages obtained from StarOddi and iButton data loggers $(\mathrm{n}=23$ cows for iButton $\mathrm{H}$ model vs. StarOddi comparison, and $\mathrm{n}=31$ cows for iButton L model vs. StarOddi; 1 value/cow per logger) using mixed and regression analyses. Mixed models (PROC MIXED) with variance components as the covariance structure, logger type as a fixed effect, and cow as a random effect were used. Degrees of freedom were estimated using containment method ( $\mathrm{df}$ test $=1 \mathrm{df}$ error $=22$ and 30 , for $\mathrm{H}$ and $\mathrm{L}$ models, respectively). Regression models (PROC REG) were used to generate 3 parameters: the coefficient of determination $\left(\mathrm{R}^{2}\right)$ and whether the slope and intercept differed from 1 and 0 , respectively.

To test whether the iButtons correctly categorized cows experiencing elevated BT, we compared daily VT 


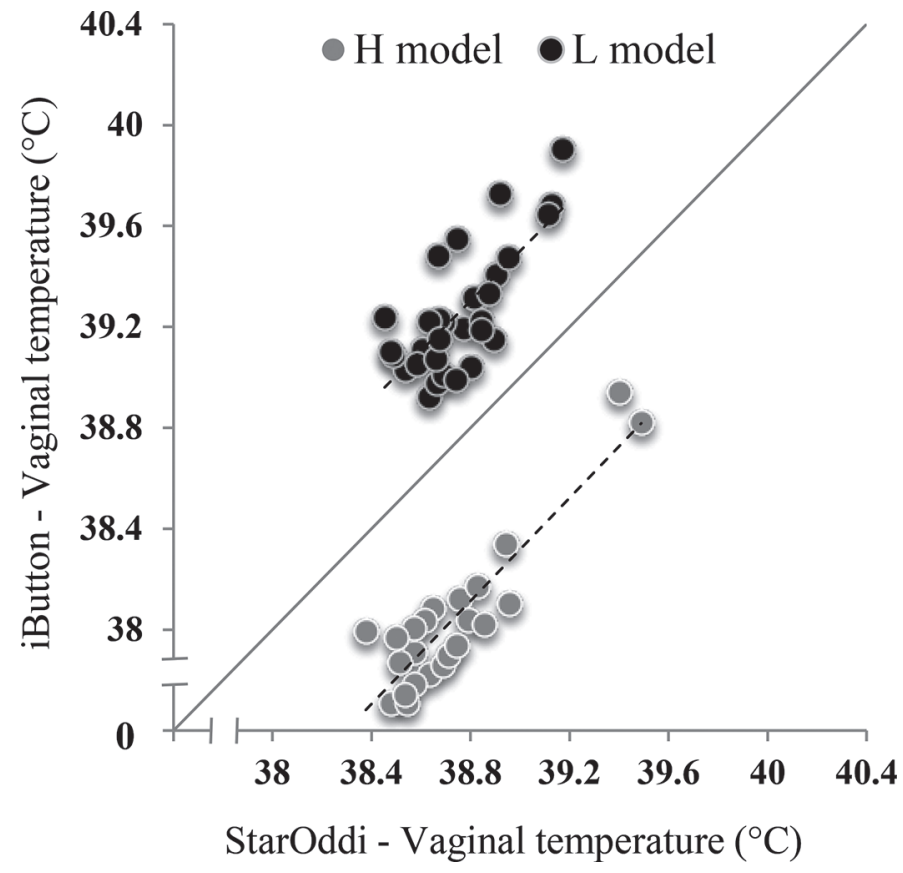

Figure 2. Relationship of vaginal temperature $\left({ }^{\circ} \mathrm{C}\right)$ between StarOddi DST centi-T (StarOddi, Gardabaer, Iceland) and 2 models of iButton loggers: DS1921H (H model) or DS1922L (L model) (Embedded Data Systems, Lawrenceburg, KY). Straight solid line (gray) represents a perfect relationship $($ slope $=1$, intercept $=0$ ). Each point represents one cow $(\mathrm{n}=23$ for $\mathrm{H}$ model, and $\mathrm{n}=31$ for $\mathrm{L}$ model), in which data were averaged across $12 \mathrm{~d}$ (range: 6 to $24 \mathrm{~d}$ ).

averages from each cow $(\mathrm{n}=274$ measurements for iButton $\mathrm{H}$ model vs. StarOddi; $\mathrm{n}=408$ measurements for iButton L model vs. StarOddi) using kappa coefficient of concordance ( $\kappa$; PROC FREQ, using TEST KAPPA statement). We aimed to compare temperature thresholds that define fever or hyperthermia across studies: $38.9,39.2,39.5,39.7$, and $40^{\circ} \mathrm{C}$. StarOddi data loggers were used as the gold standard; our research team validated their accuracy using a water bath test (data not shown).
Sampling Strategy. Daily estimates of mean VT generated using 11 different sampling strategies were obtained for each cow $(\mathrm{n}=20)$ and then compared with averages from 1-min recordings using regression analysis as described above. The 11 sampling strategies were every $5,10,15,30,45,60$ or $120 \mathrm{~min}, 1 \times / \mathrm{d}$ at 0700 or $1700 \mathrm{~h}, 2 \times / \mathrm{d}(0700$ and $1700 \mathrm{~h})$, or $3 \times / \mathrm{d}$ $(0700,1200$, and $1700 \mathrm{~h})$. The iButton and sampling strategy VT outcomes were considered accurate when: $\mathrm{R}^{2} \geq 0.9$, slope $\sim 1$, and intercept $\sim 0(P \geq 0.05)$ in the regression models.

\section{RESULTS}

\section{Weather}

Daily weather conditions for the period when BT was recorded during the $3 \mathrm{yr}$ are summarized in Table 1 . No rainfall was recorded at any time.

\section{Logger Comparison}

Compared with StarOddi loggers, the iButton $\mathrm{H}$ model underestimated VT by $0.7^{\circ} \mathrm{C}$ (38.7 vs. $38.0 \pm$ $\left.0.06^{\circ} \mathrm{C}, P<0.001\right)$, whereas the $\mathrm{L}$ model overestimated it by $0.5^{\circ} \mathrm{C}\left(38.7\right.$ vs. $\left.39.2 \pm 0.04^{\circ} \mathrm{C}, P<0.001\right)$. These differences were also captured by the regression analysis: $R^{2}$ values were 0.81 and 0.54 for the $H$ and $L$ models, respectively (Figure 2). The slopes and intercepts ranged from 0.98 to 1.02 , and from -1.42 to 0.98 , respectively $(P \geq 0.720)$.

One of the 2 data loggers compared did not record any VT values $\geq 39.7^{\circ} \mathrm{C}$ (the iButton $\mathrm{H}$ model in 2016 and the StarOddi in 2017), thus $\kappa$ coefficients were not calculated for those thresholds. When considering all other elevated VT thresholds, iButtons did not correctly classify animals. The $\kappa$ coefficients were never greater than 0.35 and 0.14 for the $\mathrm{H}$ and $\mathrm{L}$ models, respectively (Table 2 ).

Table 1. Summary of 24 -h weather conditions during the data collection period [mean, minimum (Min), and maximum (Max) daily averages] for 3 yr (2015-2017)

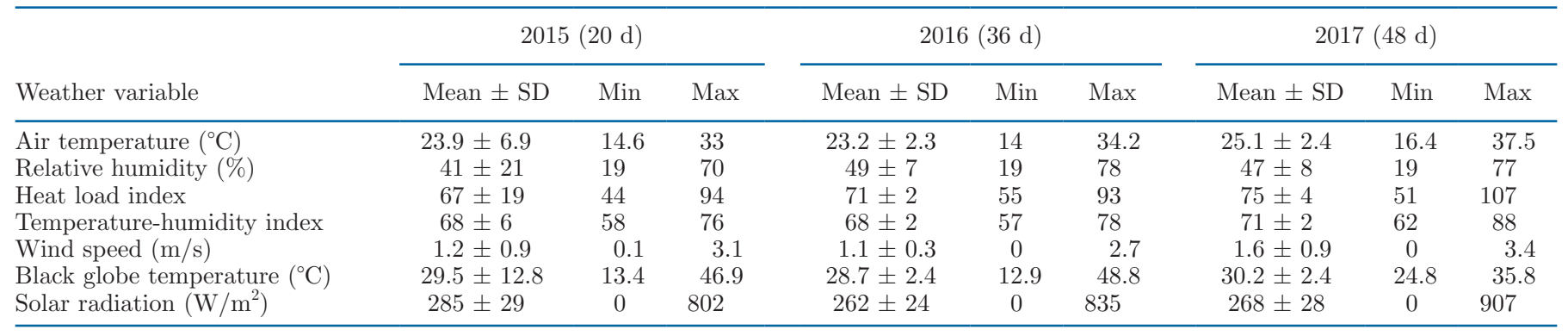


Table 2. Kappa coefficients of concordance (95\% CI) for each iButton (DS1921H and DS1922L models; Embedded Data Systems, Lawrenceburg, KY) compared with StarOddi DST centi-T loggers (StarOddi, Gardabaer, Iceland) using 3 categories of vaginal temperature thresholds

\begin{tabular}{lcrlrr}
\hline $\begin{array}{l}\text { Temperature } \\
\text { threshold }\end{array}$ & \multicolumn{2}{c}{ DS1921H } & & \multicolumn{2}{c}{ DS1922L } \\
\cline { 2 - 3 } \cline { 5 - 6 }$\left({ }^{\circ} \mathrm{C}\right)$ & $\kappa$ & $95 \%$ CI & & $\kappa$ & $95 \%$ CI \\
\hline$>38.9$ & 0.29 & $(0.16$ to 0.42$)$ & & 0.07 & $(0.05$ to 0.10$)$ \\
$>39.2$ & 0.35 & $(0.12$ to 0.58$)$ & & 0.14 & $(0.09$ to 0.19$)$ \\
$>39.5$ & 0.14 & $(-0.10$ to 0.38$)$ & & 0.05 & $(-0.00$ to 0.11$)$ \\
\hline
\end{tabular}

\section{Sampling Strategy}

Coefficients of determination decreased when the sampling strategy was $>120 \mathrm{~min}$ (Table 3 ). In addition, when measuring VT once to thrice a day, either the slope or intercept was statistically different from 1 or 0 , respectively (Table 3), except when measuring VT at $0700 \mathrm{~h}$. Sampling strategies met all 3 criteria $\left(\mathrm{R}^{2}\right.$, slope, and intercept) when VT was recorded every $\leq 120 \mathrm{~min}$.

\section{DISCUSSION}

This is the first study to compare BT outcomes collected with different data loggers at the same location within the body, as well as sampling strategies for measuring VT in dairy cattle. Both the type of data logger and sampling strategy affected VT outcomes. A relatively small and inexpensive data logger (iButton, DS1921H and DS1922L) either under- or overestimated VT and was unable to identify cows experiencing elevated VT compared with a high-accuracy data logger (StarOddi DST centi-T). In addition, to reflect 24-h body temperature averages, VT should be measured every 120 min or more often. Measuring VT from $1 \times$ to $3 \times / \mathrm{d}$ did not result in accurate estimates.

\section{Logger Comparison}

As predicted, iButtons did not replicate VT outcomes obtained using StarOddi loggers. These low-cost data loggers either under- or overestimated VT in lactating dairy cows $\left(0.7\right.$ to $0.5^{\circ} \mathrm{C}$, respectively, for $\mathrm{H}$ and $\mathrm{L}$ models). This range is greater than treatment differences found in some cooling $\left(0.1\right.$ to $0.3^{\circ} \mathrm{C}$; Means et al., 1992; Perano et al., 2015; Chen et al., 2016a) and disease research $\left(0.6\right.$ to $0.9^{\circ} \mathrm{C}$; Benzaquen et al., 2007; Wenz et al., 2011), raising questions about the robustness of results in light of the accuracy of the device used. For example, when comparing differences in BT averages of cattle fed 2 diets, Zimbelman et al. (2010) found a greater mean difference when comparing VT than RT (0.40 vs. $\left.0.17^{\circ} \mathrm{C}\right)$. The differences in location of measurement were confounded with the accuracy of the devices: VT, $\pm 1^{\circ} \mathrm{C}$ and $\mathrm{RT}, \pm 0.1^{\circ} \mathrm{C}$. However, when comparing VT and RT results obtained using the same device, others have found that BT differences were relatively minor (Burdick et al., 2012).

Our other results also corroborate the importance of using high-accuracy loggers to measure BT. The iButtons were not able to identify cows experiencing elevated VT compared with those detected by StarOddi loggers. The $\kappa$ coefficient agreements were fair at most (Landis and Koch, 1977), ranging from 0.35 to 0.14 and from 0.14 to 0.05 for $\mathrm{H}$ and L models, respectively. The lack of agreement between data loggers suggests that using low-accuracy devices may have implications for cattle welfare. In this study, for example, if cows were monitored using iButton $\mathrm{H}$ loggers, only 8 to $21 \%$ of the daily averages of elevated BT would be captured; almost $80 \%$ of these events would be missed. In addition, interpretation of results could be affected when using low-accuracy devices. We could infer, for example, that cooling treatments were not effective in

Table 3. Daily average vaginal temperature $(\mathrm{VT}) \pm \mathrm{SD}$, coefficients of determination $\left(\mathrm{R}^{2}\right)$, intercept, and slopes for the relationships between data recorded every 1 min $\left(\right.$ mean $\mathrm{VT}=38.8 \pm 0.06^{\circ} \mathrm{C}$ ) and estimates generated using different sampling strategies

\begin{tabular}{|c|c|c|c|c|}
\hline Sampling strategy & $\mathrm{VT} \pm \mathrm{SD}\left({ }^{\circ} \mathrm{C}\right)$ & $\mathrm{R}^{2}$ & Intercept & Slope \\
\hline Every 5 min & $38.8 \pm 0.2$ & $1.00^{*}$ & $0.02^{*}$ & $1.00^{*}$ \\
\hline Every $10 \mathrm{~min}$ & $38.8 \pm 0.2$ & $1.00^{*}$ & $0.02^{*}$ & $1.00^{*}$ \\
\hline Every $15 \mathrm{~min}$ & $38.8 \pm 0.2$ & $1.00^{*}$ & $0.04^{*}$ & $1.00^{*}$ \\
\hline Every $30 \mathrm{~min}$ & $38.8 \pm 0.2$ & $1.00^{*}$ & $0.07^{*}$ & $1.00^{*}$ \\
\hline Every $45 \mathrm{~min}$ & $38.8 \pm 0.2$ & $1.00^{*}$ & $-0.09^{*}$ & $1.00^{*}$ \\
\hline Every 60 min & $38.8 \pm 0.2$ & $1.00^{*}$ & $0.01^{*}$ & $1.00^{*}$ \\
\hline Every $120 \mathrm{~min}$ & $38.8 \pm 0.2$ & $1.00^{*}$ & $-0.13^{*}$ & $1.00^{*}$ \\
\hline $3 \times / \mathrm{d}(0700,1200$, and $1700 \mathrm{~h})$ & $38.7 \pm 0.3$ & 0.89 & -7.77 & 1.20 \\
\hline $2 \times / \mathrm{d}(0700$ and $1700 \mathrm{~h})$ & $38.7 \pm 0.3$ & 0.79 & -13.77 & 1.35 \\
\hline $1 \times / d(0700 \mathrm{~h})$ & $38.5 \pm 0.2$ & 0.80 & $3.93^{*}$ & $0.89^{*}$ \\
\hline $1 \times / d(1700 \mathrm{~h})$ & $39.0 \pm 0.5$ & 0.63 & -31.47 & 1.82 \\
\hline
\end{tabular}

${ }^{*} \mathrm{R}^{2} \geq 0.9$, slope $\sim 1$, and intercept $\sim 0(P \geq 0.05)$. 
reducing $\mathrm{BT}$ in cows if monitoring them with iButton L loggers, because their VT averaged $39.2^{\circ} \mathrm{C}$. Other studies have described that cows stand up and seek cooling when their BT reaches $38.9^{\circ} \mathrm{C}$ (Hillman et al., 2005), whereas others have shown that VT of cows that can choose whether or not to use sprayed water during summer averaged from 38.7 to $38.9^{\circ} \mathrm{C}$ (Legrand et al., 2011; Chen et al., 2013). These values described in the literature are similar to results obtained when monitoring cows in this study using StarOddi loggers $\left(38.7^{\circ} \mathrm{C}\right)$.

\section{Sampling Strategy}

Measuring VT as often as every 120 min resulted in more accurate 24 -h averages than strategies that recorded it once to thrice per day. More frequent recordings are more likely to encompass the natural variation of daily temperature rhythm that has been described in the literature (Bitman et al., 1984; Kendall et al., 2006; Liang et al., 2013). Although studies using data loggers measured BT as often as every minute (Burfeind et al., 2011; Burdick et al., 2012; Suthar et al., 2013), RT is often measured few times a day (Benzaquen et al., 2007; Burfeind et al., 2011; Wenz et al., 2011), which may compromise the reliability of the values obtained. In our study, for example, measuring BT only at $0700 \mathrm{~h}$ resulted in a lower daily average for cows than if it was measured every minute $\left(38.5\right.$ vs. $\left.38.8^{\circ} \mathrm{C}\right)$. Thus, cows with relatively lower fever thresholds (e.g., $<39.5^{\circ} \mathrm{C}$ ) might be missed when measuring $\mathrm{BT}$ once a day in the early morning.

Even though more frequent measurement more reliably captures BT, it may have implications for other aspects of cattle welfare. For example, more frequent measurements may require the surgical implantation of data loggers (Lea et al., 2008; Lee et al., 2016), cause irritation or discharge (Hillman et al., 2009), or involve restraining or moving cows to the chute several times during the day (Vickers et al., 2010; Lee et al., 2016). The latter may also result in higher temperature outcomes (Chen et al., 2016b); however, more work is needed to understand the effects of handling on BT. In addition, most of the devices currently available are not viable for routine use by farmers and veterinarians. Therefore, there is a need for accurate, noninvasive devices that provide real-time information about BT.

\section{CONCLUSIONS}

Device type and sampling strategies affected estimates of daily average BT. Compared with a highaccuracy data logger (StarOddi, accuracy: $\pm 0.1^{\circ} \mathrm{C}$ ), relatively small, inexpensive, and low-accuracy loggers
(iButton, accuracy range: \pm 0.5 to $\pm 1^{\circ} \mathrm{C}$ ) under- and overestimated VT and did not correctly identify when a cow was experiencing elevated VT. Measuring VT as often as every $120 \mathrm{~min}$ resulted in more accurate 24 -h estimates of the mean value compared with strategies that recorded it once to thrice daily.

\section{ACKNOWLEDGMENTS}

We thank Alycia Drwencke for her help with data collection in 2017; Neil Willits, Doug Gisi, Maria Patino, and the staff and interns of the UC Davis Dairy and Teaching Facility, including Daniel Sehnert, Frank Sauers, and Jose Villasenor, who were all associated with University of California, Davis, at the time of this study. We gratefully acknowledge the financial support of Coordenação de Aperfeiçoamento de Pessoal de Nível Superior (CAPES, Brasilia, Brazil; process BEX 0764/12-4, awarded to G. Tresoldi), Jastro Shields Award (Davis, CA), USDA Multi-state research projects W2173 and W3173 (Washington, DC), and the infrastructure support of the Department of Animal Science, and the College of Agricultural and Environmental Sciences of the University of California, Davis. The authors have not stated any conflicts of interest.

\section{REFERENCES}

Adams, A. E., F. J. Olea-Popelka, and I. N. Roman-Muniz. 2013. Using temperature-sensing reticular boluses to aid in the detection of production diseases in dairy cows. J. Dairy Sci. 96:1549-1555. https://doi.org/10.3168/jds.2012-5822.

Araki, C. T., R. M. Nakamura, and L. W. G. Kam. 1987. Diurnal temperature sensitivity of dairy cattle in a naturally cycling environment. J. Therm. Biol. 12:23-26. https://doi.org/10.1016/0306 $-4565(87) 90019-2$.

Benzaquen, M. E., C. A. Risco, L. F. Archbald, P. Melendez, M. J. Thatcher, and W. W. Thatcher. 2007. Rectal temperature, calving-related factors, and the incidence of puerperal metritis in postpartum dairy cows. J. Dairy Sci. 90:2804-2814. https://doi.org/10 .3168/jds.2006-482.

Bitman, J., A. Lefcourt, D. L. Wood, and B. Stroud. 1984. Circadian and ultradian temperature rhythms of lactating dairy cows. J. Dairy Sci. 67:1014-1023. https://doi.org/10.3168/jds.S0022 -0302(84)81400-9.

Burdick, N. C., J. A. Carroll, J. W. Dailey, R. D. Randel, S. M. Falkenberg, and T. B. Schmidt. 2012. Development of a self-contained, indwelling vaginal temperature probe for use in cattle research. J. Therm. Biol. 37:339-343. https://doi.org/10.1016/j.jtherbio.2011 .10 .007 .

Burfeind, O., V. S. Suthar, and W. Heuwieser. 2012. Effect of heat stress on body temperature in healthy early postpartum dairy cows. Theriogenology 78:2031-2038. https://doi.org/10.1016/j .theriogenology.2012.07.024.

Burfeind, O., V. S. Suthar, R. Voigtsberger, S. Bonk, and W. Heuwieser. 2011. Validity of prepartum changes in vaginal and rectal temperature to predict calving in dairy cows. J. Dairy Sci. 94:5053-5061. https://doi.org/10.3168/jds.2011-4484.

Chen, J. M., K. E. Schütz, and C. B. Tucker. 2013. Dairy cows use and prefer feed bunks fitted with sprinklers. J. Dairy Sci. 96:50355045. https://doi.org/10.3168/jds.2012-6282. 
Chen, J. M., K. E. Schütz, and C. B. Tucker. 2016a. Cooling cows efficiently with water spray: Behavioral, physiological, and production responses to sprinklers at the feed bunk. J. Dairy Sci. 99:4607-4618. https://doi.org/10.3168/jds.2015-10714.

Chen, J. M., K. E. Schütz, and C. B. Tucker. 2016b. Sprinkler flow rate affects dairy cattle avoidance of spray to the head, but not overall, in an aversion race. Appl. Anim. Behav. Sci. 179:23-31. https://doi.org/10.1016/j.applanim.2016.03.007.

Drillich, M., O. Beetz, A. Pfützner, M. Sabin, H. J. Sabin, P. Kutzer, H. Nattermann, and W. Heuwieser. 2001. Evaluation of a systemic antibiotic treatment of toxic puerperal metritis in dairy cows. J. Dairy Sci. 84:2010-2017. https://doi.org/10.3168/jds.S0022 -0302(01)74644-9.

Drwencke, A. M., G. Tresoldi, M. M. Stevens, V. Narayanan, A. V. Carrazco, F. M. Mitloehner, T. E. Pistochini, and C. B. Tucker. 2020. Innovative cooling strategies: Dairy cow responses and water and energy use. J. Dairy Sci. 103:5440-5454. https://doi.org/10 3168/jds.2019-17351.

Gaughan, J. B., T. L. Mader, S. M. Holt, and A. Lisle. 2008. A new heat load index for feedlot cattle. J. Anim. Sci. 86:226-234. https: //doi.org/10.2527/jas.2007-0305.

Hillman, P. E., K. G. Gebremedhin, S. T. Willard, C. N. Lee, and A. D. Kennedy. 2009. Continuous measurements of vaginal temperature of female cattle using a data logger encased in a plastic anchor. Appl. Eng. Agric. 25:291-296. https://doi.org/10.13031/ 2013.26332.

Hillman, P. E., C. N. Lee, and S. T. Willard. 2005. Thermoregulatory responses associated with lying and standing in heat-stressed dairy cows. Trans. ASAE 48:795-801. https://doi.org/10.13031/ 2013.18322 .

Hoffmann, G., M. Schmidt, C. Ammon, S. Rose-Meierhofer, O. Burfeind, W. Heuwieser, and W. Berg. 2013. Monitoring the body temperature of cows and calves using video recordings from an infrared thermography camera. Vet. Res. Commun. 37:91-99. https: //doi.org/10.1007/s11259-012-9549-3.

Howard, J. T., S. D. Kachman, M. K. Nielsen, T. L. Mader, and M. L. Spangler. 2013. The effect of myostatin genotype on body temperature during extreme temperature events. J. Anim. Sci. 91:3051-3058. https://doi.org/10.2527/jas.2012-6180.

Igono, M. O., B. J. Steevens, M. D. Shanklin, and H. D. Johnson. 1985. Spray cooling effects on milk production, milk, and rectal temperatures of cows during a moderate temperate summer season. J. Dairy Sci. 68:979-985. https://doi.org/10.3168/jds.S0022 $-0302(85) 80918-8$.

Kaufman, J. D., A. M. Saxton, and A. G. Rius. 2018. Short communication: Relationships among temperature-humidity index with rectal, udder surface, and vaginal temperatures in lactating dairy cows experiencing heat stress. J. Dairy Sci. 101:6424-6429. https:/ /doi.org/10.3168/jds.2017-13799.

Kelly, C. F., and T. E. Bond. 1971. Bioclimatic factors and their measurement. Page 77 in A Guide to Environmental Research on Animals. National Academies Press, Washington, DC.

Kendall, P. E., P. P. Nielsen, J. R. Webster, G. A. Verkerk, R. P. Littlejohn, and L. R. Matthews. 2006. The effects of providing shade to lactating dairy cows in a temperate climate. Livest. Sci. 103:148-157. https://doi.org/10.1016/j.livsci.2006.02.004.

Kendall, P. E., G. A. Verkerk, J. R. Webster, and C. B. Tucker. 2007. Sprinklers and shade cool cows and reduce insect-avoidance behavior in pasture-based dairy systems. J. Dairy Sci. 90:3671-3680. https://doi.org/10.3168/jds.2006-766.

Landis, J. R., and G. G. Koch. 1977. The measurement of observer agreement for categorical data. Biometrics 33:159-174. https://doi .org $/ 10.2307 / 2529310$.

Lea, J. M., D. D. O. Niemeyer, M. T. Reed, A. D. Fisher, and D. M. Ferguson. 2008. Development and validation of a simple technique for logging body temperature in free-ranging cattle. Aust. J. Exp. Agric. 48:741-745. https://doi.org/10.1071/EA07422.

Lee, Y., J. D. Bok, H. J. Lee, H. G. Lee, D. Kim, I. Lee, S. K. Kang, and Y. J. Choi. 2016. Body temperature monitoring using subcutaneously implanted thermo-loggers from Holstein steers. Asian-
Australas. J. Anim. Sci. 29:299-306. https://doi.org/10.5713/ajas .15 .0353 .

Legrand, A., K. E. Schütz, and C. B. Tucker. 2011. Using water to cool cattle: Behavioral and physiological changes associated with voluntary use of cow showers. J. Dairy Sci. 94:3376-3386. https:// doi.org/10.3168/jds.2010-3901.

Liang, D., C. L. Wood, K. J. McQuerry, D. L. Ray, J. D. Clark, and J. M. Bewley. 2013. Influence of breed, milk production, season, and ambient temperature on dairy cow reticulorumen temperature. J. Dairy Sci. 96:5072-5081. https://doi.org/10.3168/jds.2012-6537.

Means, S. L., R. A. Bucklin, R. A. Nordstedt, D. K. Beede, D. R. Bray, C. J. Wilcox, and W. K. Sanchez. 1992. Water application rates for sprinklers and fan dairy cooling system in hot, humid climates. Trans. ASAE 8:374-378. https://doi.org/10.13031/2013.26080.

Miura, R., K. Yoshioka, T. Miyamoto, H. Nogami, H. Okada, and T. Itoh. 2017. Estrous detection by monitoring ventral tail base surface temperature using a wearable wireless sensor in cattle. Anim. Reprod. Sci. 180:50-57. https://doi.org/10.1016/j.anireprosci.2017 .03 .002 .

Overton, M. W., W. M. Sischo, and J. P. Reynolds. 2003. Evaluation of effect of estradiol cypionate administered prophylactically to postparturient dairy cows at high risk for metritis. J. Am. Vet. Med. Assoc. 223:846-851. https://doi.org/10.2460/javma.2003.223 .846 .

Perano, K. M., J. G. Usack, L. T. Angenent, and K. G. Gebremedhin. 2015. Production and physiological responses of heat-stressed lactating dairy cattle to conductive cooling. J. Dairy Sci. 98:52525261. https://doi.org/10.3168/jds.2014-8784.

Pohl, A., S. Bertulat, S. Borchardt, O. Burfeind, and W. Heuwieser. 2016. Randomized, controlled clinical trial on the efficacy of nonsteroidal antiinflammatory drugs for the treatment of acute puerperal metritis in dairy cows. J. Dairy Sci. 99:8241-8249. https:// doi.org/10.3168/jds.2015-10775.

Pohl, A., W. Heuwieser, and O. Burfeind. 2014. Technical note: Assessment of milk temperature measured by automatic milking systems as an indicator of body temperature and fever in dairy cows. J. Dairy Sci. 97:4333-4339. https://doi.org/10.3168/jds.2014-7997.

Polsky, L. B., A. M. L. Madureira, E. L. D. Filho, S. Soriano, A. F. Sica, J. L. M. Vasconcelos, and R. L. A. Cerri. 2017. Association between ambient temperature and humidity, vaginal temperature, and automatic activity monitoring on induced estrus in lactating cows. J. Dairy Sci. 100:8590-8601. https://doi.org/10.3168/ jds.2017-12656.

SAS Institute. 2014. SAS 9.4 Language Reference: Concepts. Page 828. SAS Institute Inc., Cary, NC.

Smith, B. I., G. A. Donovan, C. Risco, R. Littell, C. Young, L. H. Stanker, and J. Elliott. 1998. Comparison of various antibiotic treatments for cows diagnosed with toxic puerperal metritis. J. Dairy Sci. 81:1555-1562. https://doi.org/10.3168/jds.S0022 -0302(98)75721-2.

Suthar, V., O. Burfeind, S. Bonk, R. Voigtsberger, C. Keane, and W. Heuwieser. 2012. Factors associated with body temperature of healthy Holstein dairy cows during the first 10 days in milk. J. Dairy Res. 79:135-142. https://doi.org/10.1017/S0022029911000896.

Suthar, V., O. Burfeind, B. Maeder, and W. Heuwieser. 2013. Agreement between rectal and vaginal temperature measured with temperature loggers in dairy cows. J. Dairy Res. 80:240-245. https:// doi.org/10.1017/S0022029913000071.

Suthar, V. S., O. Burfeind, J. S. Patel, A. J. Dhami, and W. Heuwieser. 2011. Body temperature around induced estrus in dairy cows. J. Dairy Sci. 94:2368-2373. https://doi.org/10.3168/jds.2010 -3858 .

Tresoldi, G., K. E. Schütz, and C. B. Tucker. 2018. Cooling cows with sprinklers: Timing strategy affects physiological responses to heat load. J. Dairy Sci. 101:11237-11246. https://doi.org/10.3168/jds .2018-14917.

Tresoldi, G., K. E. Schütz, and C. B. Tucker. 2019. Cooling cows with sprinklers: Effects of soaker flow rate and timing on behavioral and physiological responses to heat load and production. J. Dairy Sci. 102:528-538. https://doi.org/10.3168/jds.2018-14962. 
Vickers, L. A., O. Burfeind, M. A. G. von Keyserlingk, D. M. Veira, D. M. Weary, and W. Heuwieser. 2010. Technical note: Comparison of rectal and vaginal temperatures in lactating dairy cows. J. Dairy Sci. 93:5246-5251. https://doi.org/10.3168/jds.2010-3388.

Wenz, J. R., D. A. Moore, and R. Kasimanickam. 2011. Factors associated with the rectal temperature of Holstein dairy cows during the first 10 days in milk. J. Dairy Sci. 94:1864-1872. https://doi.org/ 10.3168/jds.2010-3924.

West, J. W., B. G. Mullinix, and J. K. Bernard. 2003. Effects of hot, humid weather on milk temperature, dry matter intake, and milk yield of lactating dairy cows. J. Dairy Sci. 86:232-242. https://doi .org/10.3168/jds.S0022-0302(03)73602-9.
Zimbelman, R. B., L. H. Baumgard, and R. J. Collier. 2010. Effects of encapsulated niacin on evaporative heat loss and body temperature in moderately heat-stressed lactating Holstein cows. J. Dairy Sci. 93:2387-2394. https://doi.org/10.3168/jds.2009-2557.

\section{ORCIDS}

Grazyne Tresoldi @ https://orcid.org/0000-0002-0069-2882

Karin E. Schütz @ https://orcid.org/0000-0002-2893-3465

Cassandra B. Tucker (1) https://orcid.org/0000-0002-6014-444X 